Please do not remove this page

RMIT

UNIVERSITY

\title{
Increasing the salience of NRM Research with innovative methodologies: The example of oriented qualitative case study (OQCS)
}

McLennan, Blythe; Garvin, T

https://researchrepository.rmit.edu.au/esploro/outputs/9921858147701341/filesAndLinks?institution=61RMIT_INST\&index=null

McLennan, B., \& Garvin, T. (2012). Increasing the salience of NRM Research with innovative methodologies: The example of oriented qualitative case study (OQCS). Society and Natural Resources, 25, 400-409. https://doi.org/10.1080/08941920.2011.557827

Document Version: Accepted Manuscript

Published Version: https://doi.org/10.1080/08941920.2011.557827

Repository homepage: https://researchrepository.rmit.edu.au

(C) 2011 Taylor \& Francis Group

Downloaded On 2023/04/26 12:07:01 +1000

Please do not remove this page 
Thank you for downloading this document from the RMIT Research Repository.

The RMIT Research Repository is an open access database showcasing the research outputs of RMIT University researchers.

RMIT Research Repository: http://researchbank.rmit.edu.au/

\section{Citation:}

McLennan, B and Garvin, T 2012, 'Increasing the salience of NRM Research with innovative methodologies: The example of oriented qualitative case study (OQCS)', Society and Natural Resources, vol. 25, no. 4, pp. 1-10.

See this record in the RMIT Research Repository at: http://researchbank.rmit.edu.au/view/rmit:15817

Version: Accepted Manuscript

Copyright Statement: (c) 2011 Taylor \& Francis Group

Link to Published Version:

http://dx.doi.org/10.1080/08941920.2011.557827

\section{PLEASE DO NOT REMOVE THIS PAGE}


This is an Author's Accepted Manuscript of an article published in:

McLennan, Blythe J., \& Garvin, Theresa. (2012). Increasing the Salience of NRM Research With Innovative Methodologies: The Example of Oriented Qualitative Case Study (OQCS). Society \& Natural Resources, 25(4), 400-409. doi: 10.1080/08941920.2011.557827.

\title{
Increasing the salience of NRM research with innovative methodologies: the example of Oriented Qualitative Case Study (OQCS)
}

\author{
Blythe J. McLennan ${ }^{\mathrm{a}}$ and Theresa Garvin ${ }^{\mathrm{b}}$ \\ ${ }^{a}$ Centre for Risk and Community Safety, School of Mathematical and Geospatial Sciences, RMIT \\ University, Melbourne, Victoria, Australia; blythe.mclennan@rmit.edu.au \\ ${ }^{\mathrm{b}}$ Community, Health and Environment Research Centre, Department of Earth \& Atmospheric \\ Sciences, University of Alberta, Edmonton, Alberta, Canada
}

\begin{abstract}
Recent approaches in natural resource management emphasize decision makers' need for research that (1) encompasses a landscape or regional scale, (2) uses multiple scales of analysis, and (3) has a relatively timely research process. This article presents a novel qualitative research methodology that seeks to increase research salience (relevance) for decision makers in natural resource management agencies by taking steps toward meeting these needs. Called oriented qualitative case study (OCQS), the methodology was used to examine how and why landholders changed their land uses and livelihoods during a forest transition in North West Costa Rica. In order to better meet the three needs listed above this methodology makes a necessary, partial trade-off in the depth of knowledge it generates at smaller scales. In addition to using such novel methodologies, ongoing engagement between researchers, decision makers and other stakeholders is also critical for increasing salience.
\end{abstract}

\section{Introduction}

This article presents a novel qualitative methodology that was used to examine land use and livelihood changes made by private landholders during a forest transition (the turnaround from net deforestation to net forest recovery). The methodology, which we refer to as Oriented Qualitative Case Study (OQCS), is a case-oriented research approach that uses qualitative data collection and analysis methods to examine a single, regional-scale case at multiple scales of analysis and in a relatively timely manner. A key reason for using a novel methodology in this project was to produce information at the appropriate scales and timelines to increase its salience for decision makers in natural resource management agencies.

\section{Background}

\section{The Challenge of Salience}

Much research in the field of natural resource management (NRM) can be considered applied (use- or action-oriented) research as it aims to support decision-making. In contrast to basic (also fundamental or 'pure') research, the quality of applied research can be multi-faceted. Cash et al. (2002) identified three key quality components of applied research: credibility, 
salience and legitimacy. These authors define credibility as the trustworthiness of the research process and findings; salience as the relevance of research to decision makers and the public; and legitimacy as fair treatment based on different values, concerns and perspectives. ${ }^{1}$

Credibility is the dominant concern when gauging the quality of basic research, whereas applied research prioritises salience and legitimacy more highly. If credibility is prioritized in applied research while disregarding salience and legitimacy research ends up ignored by its intended end user and ultimately has little impact (Cash et al. 2002). As a result achieving a higher degree of salience and legitimacy can often require a partial trade-off in credibility (Cash et al. 2002). This is often the case when, for example, decision-makers need information faster than researchers can produce it (see for example Szaro and Peterson 2004). Therefore, researchers conducting applied research may be required to accept a lesser degree of credibility than would be acceptable in basic research in order to make gains in other facets.

Salience is generally higher when research is conducted at appropriate scales and timelines for decision makers. According to Cash et al. (2002), "Information that arrives at the wrong time in the evolution of an issue (too early, or too late), or that is too broad or narrow in scope, or is not at the right scale for a decision maker, also can fail to influence action for lack of salience" (p.4). Although not the only factors important for determining salience, conducting research at inappropriate scales and timelines can seriously undermine the impact of applied research studies.

In natural resource management, the scales and timelines that are most relevant for decision makers vary depending on the management scenario. However, recent approaches increasingly emphasize decision makers' need for research that: 1) encompasses a landscape or regional scale; 2) uses multiple scales of analysis, and; 3) has a timely research process. Proponents of integrated natural resource management (INRM) (Sayer and Campbell 2001), adaptive natural resource management (Morghan et al. 2006) and ecosystem management (Szaro and Peterson 2004) emphasize the need for research of complex human-environment systems that integrates multiple spatial and temporal scales (including regional and landscape scales), and that produces results quickly enough to link into the ongoing learning cycles of decision makers. Proponents also recognize that such research may not be able to achieve the same degree of credibility as basic research, and that it may require new methodologies (Morghan et al. 2006; Mills and Clark 2001; Szaro and Peterson 2004).

These scale and timeline needs pose a particular challenge for qualitative projects. Much qualitative research is case-oriented (Mahoney and Goertz 2006): it aims to investigate a specific, in-depth example of a phenomenon by examining it holistically and within its natural setting (Stake 1995, p.1-13; Yin 1994, p.11-15). However case-oriented qualitative research is not well-suited to encompassing multiple scales of analysis and using a timely research process. Because qualitative research in general prioritises depth over breadth, it tends to be better-suited to smaller study areas. Strategies do exist for conducting qualitative studies at larger scales but they tend to either lose sensitivity to differences at smaller scales or increase timelines (Yin 1994, p.45; Poteete and Ostrom 2008).

While timelines in regional-scale, case-oriented research can be reduced, it generally comes at a cost. For example, teams of researchers could be used but would require more resources than is typically available (Yin 1994, p.45; Poteete and Ostrom 2008). Rapid appraisal methods could also be employed to collect and analyse data (McNall and Foster-Fishman 2007), which have the

\footnotetext{
${ }^{1}$ Definitions of research, including concepts of credibility, trustworthiness and salience, vary according to epistemological, theoretical and methodological approaches (Lincoln and Guba 2005), for that reason we adopt the definitions of Cash et al. 2002.
} 
added advantage of increasing stakeholder participation, control and ownership within a research project. However, rapid appraisal methods may not always be the most suitable, depending on the goal and context of the specific project. For example, it may not be possible for researchers to bring the 'right' people together to take part in the group-based data collection methods that are common in participatory rural appraisal (PRA) because of distance and transportation restrictions (Leurs 1996).

In the end, balancing salience, credibility and legitimacy depends on understanding the socio-spatial and political arena in which the research question is posed, the administrative milieu within which managers are positioned, and the timelines within which questions must be answered. All of these require situated (some might say 'subjective') understandings of the context at regional, community, and administrative scales. Answers must flow easily across these different boundaries, and have salience and legitimacy in these multiple contexts.

\section{Introducing Oriented Qualitative Case Study}

Oriented Qualitative Case Study (OQCS) is a new method that moves iteratively between regional and local scales in order to meet the needs of NRM managers, while incorporating both depth and breadth in the research process. The project described in the following section incorporates two primary scales of analysis: a larger case scale (region) and a smaller sub-case scale (geographic communities). Using these two scales of analysis, our OQCS project consisted of five key steps (see also Figure 1).

- Step 1: Preliminary case review - An overview of the regional context that familiarises the researcher with the study area and aids in the selection of sub-cases (communities).

- Step 2: Reference study - An in-depth study of a single, illustrative community that produces baseline data and enables streamlined studies of comparison communities.

- Step 3: Regional case review - Interviews are conducted with regional managers and policymakers, and results from the reference study are contextualized and cross-checked with interview results.

- Step 4: Comparison studies - Results from reference community form the basis of questioning in comparison communities; less data is collected from fewer participants in comparison communities and is compared to the reference community.

- Step 5: Multi-scale analysis - Data from all four previous steps are reviewed and crosschecked to provide a region-wide explanation for the phenomenon under study.

The process builds and expands on a similar approach used in agent-based land-use change modelling studies to scale up models to a regional area (see for example Castella et al. 2005). A critical quality measure in the land-use model was also incorporated into OQCS: the crosschecking of the findings from smaller, community scales (comparison studies) against a data collected from the larger scale (regional case review). This serves as a form of cross-scale triangulation and increases the credibility of the findings while shortening research timelines. 
Figure 1: Key stages/components of the research process in OQCS (shown in grey). Numbers indicate the order of the research process.

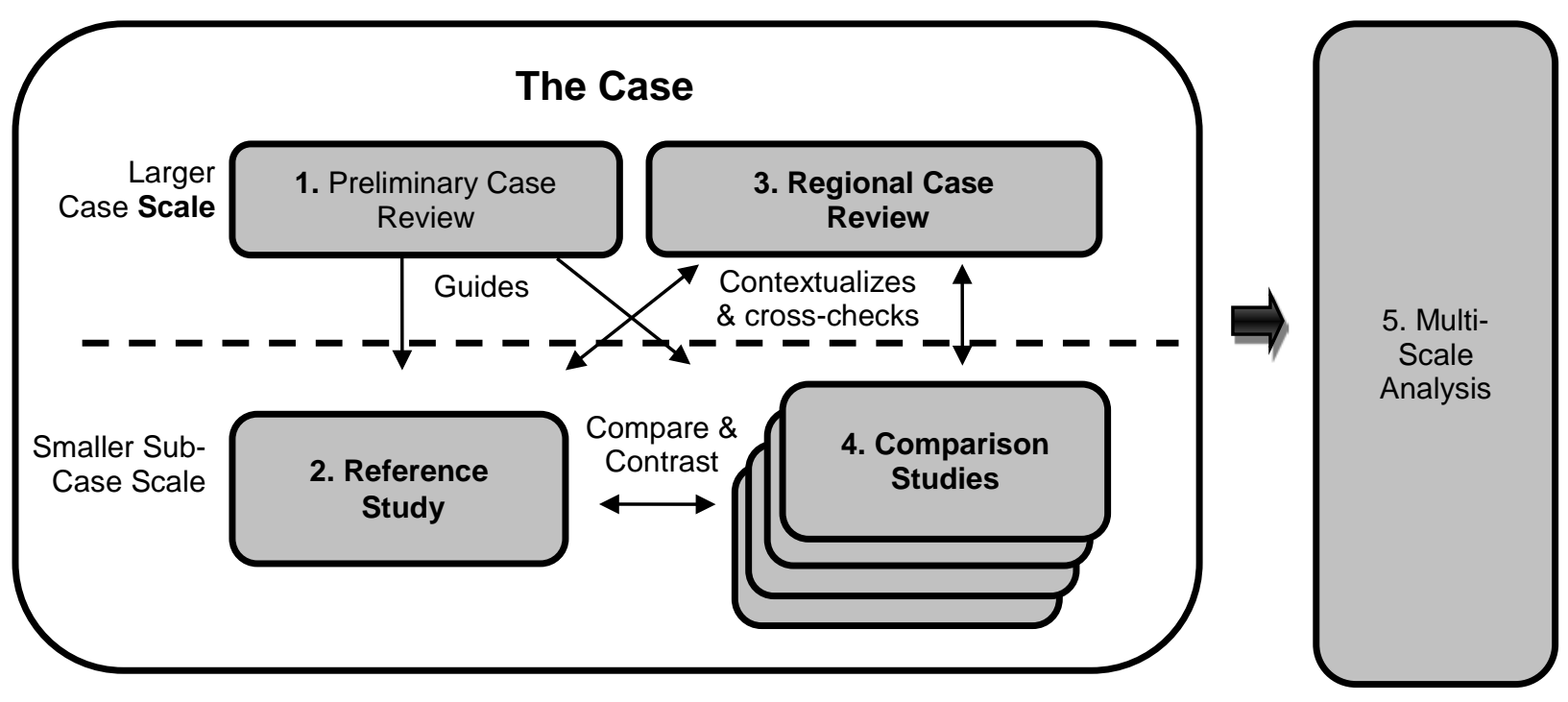

\section{Example of an Oriented Qualitative Case Study}

In the example described here, OQCS was used to 'look inside' a regional-scale forest transition to examine how and why landholders' land use practices and livelihood strategies varied within the region, and to consider the implications for forest conservation and sustainability. The case study was conducted in Costa Rica's dry North West, which is a tropical dry, lowland area of the northern Pacific region in the province of Guanacaste. Since Spanish conquest, land use in this area has been dominated by expansive cattle-grazing: initially on large cattle ranches (haciendas), and more recently on smaller, mixed-use farms. Since the 1980s, socioeconomic changes have significantly impacted forest cover and rural livelihoods in this region (Calvo-Alvarado et al. 2009).

In the context of this project, we use the term 'community' to refer to geographicallydistinct localities while also acknowledging that any attempt to define the concept of community is problematic. The project focused on landholders with small and medium-sized properties because they are more numerous than large landholders in the study area, and because they are more likely to experience adverse impacts as a result of large-scale socioeconomic change (see for example Woods 2007).

The primary, traditional land use and livelihood strategy was the same in all the communities: cattle-grazing using mainly non-mechanized farming methods. However, the local land-use context in each of the communities differed in characteristics such as population size, geographic position, primary method of land acquisition (e.g. government distributed or purchased/inherited) and average property sizes.

For this project, we chose to use a qualitative research approach because it facilitates understanding of social processes and enables the researcher to identify the impact of contextual conditions (Mahoney and Goertz 2006, p.1-13; Stake 1995). We developed OQCS as a way of integrating issues of scale into existing qualitative research methods. Specifically, we wanted to incorporate a regional scale in order to better match the scales of the community-based change with existing government-led forest conservation programs administered through regional 
Conservation Areas. We also wanted the community-scale analysis to identify similarities and differences in land use and livelihood dynamics arising due to differences in local land-use contexts. Finally, we wanted to produce research findings quickly enough to be accessible to government agencies involved in promoting forest conservation. As the project was a component of a larger doctoral research project, data collection and analysis were confined to a single researcher.

\section{Research Process}

In this project, data collection began in an initial two-week field visit in January 2007. Informal (unrecorded) interviews with policymakers and selected landholders were conducted at this time, and limited secondary data collected for the preliminary case review. Additional informal interviews and all formal (recorded) interviews were conducted during a primary 4 month fieldwork period from April to July of 2007. All formal interviews were conducted in the participant's first language (Spanish in the case of all but one interview), and were recorded onsite with a handheld digital recording device. In all, the total time required for data collection was approximately 4 months, and data were analyzed in an additional 2 months, making the total timeline for the research project approximately 6 months.

\section{Step 1. Preliminary Case Review}

The preliminary case review was conducted at the regional scale (see Figure 1) and data collected to identify regional patterns of land use, livelihood factors, and forest cover change. Data was gathered from secondary sources such as peer-reviewed research studies, government documents, census data and print media, as well as through preliminary, informal interviews with representatives from relevant regional government and industry offices. The researcher summarised the interviews in field notes. The preliminary case review took approximately four weeks of the total fieldwork time.

\section{Step 2. Reference Study}

The reference study was an exploratory, in-depth study of one community ('Reference Community') situated within the region. The Reference Community was selected to be a 'critical' negative case of land-use and livelihood change (Yin 1994, p.23) and produced rich baseline data that was later used in the comparison studies. The community was selected because landholders' livelihoods in this community were impacted particularly negatively by the socioeconomic changes occurring during the forest transition period. This was reported by representatives of regional government offices involved in agrarian and community development, and was later confirmed by interviews with landholders and community leaders.

Interviews in the reference study were semi-structured, open and exploratory to allow new and unanticipated information to emerge. Sampling was purposive, with participants selected through a mix of snowball and maximum variation sampling. ${ }^{2}$ Initial participants were recommended by a local member of a regional Cattlemen's Association. All participation was completely voluntary, and participants were able to withdraw from the study at any time with no consequences. Participants were asked about their own livelihood strategies and land-use practices as well as those of others in the community. Interviewing continued until data saturation (e.g. no new relevant information was emerging in subsequent interviews) (Miles and Huberman 1994, p. 74). As land-use practices and livelihood strategies were very similar

\footnotetext{
${ }^{2}$ In purposive sampling the researcher selects participants that have direct knowledge of issues relevant to fulfilling the research goals. Maximum variation sampling seeks out participants with the widest range of perspectives, knowledge and experiences; in snowball sampling participants identify other people who have knowledge of the issues of interest to the researcher (see Kvale 1996).
} 
amongst landholders, strong patterns quickly emerged in the interviews and data saturation was achieved with a relatively small sample of 15 participants (13 current or former landholders and 2 community leaders). A preliminary analysis of these interviews was conducted in the field based on field notes and then used to structure the interview guide for the comparison studies discussed in Step 4. On completion of the fieldwork, interviews were transcribed verbatim in the original language for later analysis in Step 5. Data collection and the preliminary analysis of interviews in the field took approximately four weeks to complete. Transcribing the interviews took approximately two and a half weeks.

\section{Step 3. Regional Case Review}

The regional case review consisted of semi-structured interviews with 12 representatives of regional government agencies, industry organizations and an environmental organization. Relevant agencies and organizations were identified in the preliminary case review (Step 1). The interviews asked respondents to identify drivers of regional patterns in land use, livelihood and forest cover changes. They also asked respondents to explain how government agencies and industry groups sought to influence landholders’ practices. Interviews were summarised in English to reduce transcription time. The total time taken to contact participants and collect data was approximately four weeks. Summarizing the interviews took approximately one week.

\section{Step 4. Comparison Studies}

Comparison studies were conducted in five of the nine additional communities located in the study area ('Comparison Communities'). Comparison Communities were selected to provide wide geographical coverage of the tropical dry ecological zone and immediate surrounds. Fewer interviews were conducted in comparison communities, with 14 landholders and four community leaders interviewed in total across all four Comparison Communities. Participants were once again selected purposively through a mixture of snowball and maximum variation sampling, and interviews summarised in English.

A two-part interview design was employed in the comparison communities. The first part asked open-ended questions about the local area, history, and land-use specific to the community. The second part used a set of challenges identified from Step 2 (Reference Community) and respondents were asked to identify the degree to which their own community's experience was the same or different to that found in the reference community ${ }^{3}$. The combination of more open-ended questions followed by more structured questions struck a balance between enabling participants to raise issues that were not anticipated by the researcher while also targeting and streamlining the interview process. Contacting participants and collecting data took approximately four weeks in total, and summarising the interviews took approximately a week and a half.

\section{Step 5. Multi-Scale Analysis}

The final step of the research process was a multi-scale analysis that built understanding of the larger case while remaining sensitive to differences between each of the sub-cases. Analysis began with an in-depth evaluation of the reference community to identify an appropriate conceptual framework. This was followed by an application of that framework in the comparison communities to determine the degree to which community experiences were the same or different. Data was then cross-analyzed and checked across the multiple data collection methods in order to ensure thorough understanding of the larger case.

\footnotetext{
${ }^{3}$ A complete explanation of methods, including ethics materials, sampling processes and research instruments (including interview guides) is available in McLennan, 2009.
} 
In this particular project the Sustainable Livelihoods Analysis (SLA) framework (Scoones 1998) was found to be an appropriate tool because it was produced by rural development researchers to conceptually organize factors that impact rural livelihoods in an integrated way. ${ }^{4}$ First, interview transcripts from the reference community were coded by focussing on land use and livelihood changes made during the forest transition period, and on identifying factors that had restricted or enabled those decisions. This produced a final set of codes that were then compared to the SLA framework and found to be a good fit. Analyzing the reference study data took just under four weeks.

Summarized data was then partially ordered (Miles and Huberman 1994, p. 213) into thematic matrices that listed each participant's responses relating to key elements of the SLA framework. In this study, these matrix themes included: contextual conditions impacting livelihoods (e.g. large-scale socioeconomic changes); policies, processes and institutions mediating access to livelihood resources; access to livelihood resources; and livelihood outcomes (McLennan, 2009). Responses were then grouped according to community. Data was compared and contrasted within each community and then across communities to identify similarities and differences at the community and regional scales (Miles and Huberman 1994, p. 254). Finally, as mentioned previously, the data was contextualised and cross-checked with caselevel (regional) data. This part of the analysis took approximately three weeks.

\section{Discussion}

In the example described here, the use of the Oriented Qualitative Case Study (OQCS) methodology enabled us to examine individual and community land use and livelihood changes during a forest transition and to 'scale them up' to the regional level of existing conservation policy and management programs. Furthermore, it enabled the study to be sensitive to important differences in the local land-use contexts between communities that contributed to varied livelihood outcomes. Using this methodology also enabled us to complete the research process more quickly than using a detailed qualitative research process. Given the time taken to collect and analyse data for the reference study, we estimate that we reduced the time spent collecting data by three to four months and the time spent analysing data by two months, almost halving the total research time.

Key limitations of using OQCS are that by collecting less data in the Comparison Communities we likely overlooked some locally-specific factors influencing land use and livelihoods in those communities, which may have biased the final results towards the Reference Community. The two-part interview design used in the comparison studies went some way towards offsetting these limitations because it focussed on experiences and opinions in the Comparison Communities that were different to those of the Reference Community ('negative cases', see Baxter and Eyles 1997). However, this approach cannot completely replace the use of individual, in-depth studies in each community. Thus careful selection of the reference sub-case is critical. We recommend targeting a reference sub-case that provides rich baseline data, followed by comparison sub-cases that provide maximum variation. Together this process allows for both depth and breadth of data.

By using OQCS, this project made a partial trade-off in the depth of knowledge it generated at the sub-case scale in order to encompass a regional case-scale, thereby using two scales of analysis but employing a more timely research process. This trade-off decreased the degree of

\footnotetext{
${ }^{4}$ The SLA framework was not used to frame data collection. Rather it was utilized as a valuable tool to organize and interpret data during the analysis of interviews from the Reference Community after the fieldwork was completed. Other projects might employ different frameworks as explanatory tools.
} 
credibility (trustworthiness) of the findings from the Comparison Communities, which makes this methodology unsuitable for basic research projects that prioritize the highest possible credibility. However, it also increased the salience of the findings for decision makers in regional natural resource management agencies by better matching their scales and timelines. OQCS is therefore most suitable for use in applied research projects in which a partial trade-off in credibility is acceptable in order to make gains in salience and/or legitimacy (Cash et al. 2002).

Although the importance of conducting research at the appropriate scales and timelines in order to increase salience is emphasized in this article, we are also highly aware that this does not necessarily ensure that research will be valued and used by decision makers. Ongoing engagement between researchers and decision makers throughout the research process is crucial for facilitating open communication, fostering understanding of different needs, building trust, and establishing shared expectations (Mills and Clark 2001). Unfortunately, such engagement was restricted in the project reported here. This was because of the researcher's remoteness from the study area outside of the field work period and because of unanticipated events during the fieldwork period that monopolized decision makers' time, in particular a number of large wildfires. The fact that 'in country' researchers were not employed may have, on the one hand, increased the research time because some additional time was spent orienting an outsider to communities. On the other hand, the use of an out-of-country researcher may have shortened research by providing dedicated and unimpeded research time. Regardless, the importance of local linkages should not be underestimated. In order to use this methodology most effectively in other projects, ongoing engagement with decision makers and other stakeholders should be prioritized as much as possible.

\section{Conclusion}

In conclusion, Oriented Qualitative Case Study (OQCS) has potential as a methodology for NRM research projects that want to examine a regional-scaled case using more than one scale of analysis while also prioritising a timely process. We see OQCS as a valuable addition to the existing suite of qualitative methodologies that are already used in NRM research. As with all methodologies, the strengths and limitations of OQCS make it better-suited to some research projects than others. Therefore, we do not see OQCS as being necessarily better than existing methodologies but an alternative that may be better-suited for some projects. We do believe that OQCS goes a small way towards extending the existing repertoire and applications of qualitative methodologies in NRM research. In particular, the use of OQCS may increase the salience of research findings for NRM decision makers by enabling qualitative research to be conducted at the appropriate scales and timelines to better inform decision making in natural resource agencies.

\section{Acknowledgements}

The authors would like to acknowledge the contributions of Dr Julio Calvo-Alvarado (Instituto Tecnológico de Costa Rica) and Dr Arturo Sanchez-Azofeifa (University of Alberta) to this research. This project was carried out with the aid of grants from: University of Alberta International's Fund for Support of Development Activities (FSIDA); Tropi-Dry (Inter-American Institute for Global Change Research [IAI] CRN II \#21); and the Social Science and Humanities Research Council (SSHRC) of Canada. Many thanks to the editor and the three anonymous reviewers for their detailed and constructive feedback. Finally, many thanks to the people of Guanacaste for opening their lives, hearts and homes. 


\section{References}

Baxter, J., and J. Eyles. 1997. Evaluating qualitative research in social geography: establishing 'rigor' in interview analysis. Transactions of the Institute of British Geographers 22(4):505-525.

Calvo-Alvarado, J. C., B. McLennan, A. G. Sánchez-Azofeifa, and T. Garvin. 2009. Deforestation and forest restoration in Guanacaste, Costa Rica: putting conservation policies in context. Forest Ecology and Management 258(6):931-940.

Cash, D. W., W. C. Clark, F. Alcock, N. Dickson, N. Eckley, and J. Jäger. 2002. Salience, credibility, legitimacy and boundaries: linking research, assessment and decision making. In Faculty Research Working Papers Series. Cambridge, MA: John F. Kennedy School of Government, Harvard University.

Castella, J. C., T. N. Trung, and S. Boissau. 2005. Participatory simulation of land-use changes in the northern mountains of Vietnam: the combined use of an agent-based model, a role-playing game, and a geographic information system. Ecology and Society (1), http://www.ecologyandsociety.org/vol10/iss1/art27/.

Kvale, S., ed. 1996. Interviews: An introduction to qualitative research interviewing. Thousand Oaks, California: Sage Publications.

Leurs, R. 1996. Current challenges facing participatory rural appraisal. Public Administration and Development 16(1):57-72.

Lincoln, Y. S., and E. G. Guba. 2005. Paradigmatic controversies, contradictions, and emerging confluences. In The SAGE handbook of qualitative research, ed. N. K. Denzin and Y. S. Lincoln. Thousand Oaks, California: Sage Publications.

Mahoney, J., and G. Goertz. 2006. A tale of two cultures: Contrasting quantitative and qualitative research. Political Analysis 14:227-249.

McLennan, B. 2009. Opportunities and challenges for the pursuit of sustainability under globalization: a study from Costa Rica. PhD Thesis. Human Geography Program, Department of Earth \& Atmospheric Sciences, University of Alberta. Edmonton, AB Canada.

McNall, M., and P. G. Foster-Fishman. 2007. Methods of rapid evaluation, assessment, and appraisal. American Journal of Evaluation 28(2):151-168.

Miles, M. B., and A. M. Huberman. 1994. Qualitative data analysis: An expanded sourcebook. 2nd edn. Thousand Oaks, California: Sage Publications.

Mills, T. J., and R. N. Clark. 2001. Roles of research scientists in natural resource decision-making. Forest Ecology and Management 153(1-3):189-198.

Morghan, K. J. R., R. L. Sheley, and T. J. Svejcar. 2006. Successful adaptive management: the integration of research and management. Rangeland Ecology and Management 59(2):216-219.

Poteete, A. R., and E. Ostrom. 2008. Fifteen years of empirical research on collective action in natural resource management: struggling to build large-N databases based on qualitative research. World Development 36(1):176-195.

Sayer, J. A., and B. Campbell. 2001. Research to integrate productivity enhancement, environmental protection, and human development. In Conservation Ecology.

Scoones, I. 1998. Sustainable rural livelihoods: A framework for analysis. Brighton, UK: Institute of Development Studies.

Stake, R. E., ed. 1995. The art of case study research. Thousand Oaks, California: Sage Publications.

Szaro, R. C., and C. E. Peterson. 2004. Evolving approaches toward science-based forest management. Forest Snow and Landscape Research 78(1-2):9-20.

Woods, M. 2007. Engaging the global countryside: globalization, hybridity and the reconstitution of rural place. Progress in Human Geography 31(4):485-507.

Yin, R. K., ed. 1994. Case study research: Design and methods. 2nd edn, Applied social research methods series. Thousand Oaks, California: Sage Publications. 